\title{
Carnival and condoms
}

\section{Letter from Brazil}

\author{
John Dunn
}

Compare the following: "AIDS, Why We Won't Be Silenced." (Sunday Times, December 1993) and “. . . sex is an extremely important activity for a person's physical and mental health . . . wear a condom." (Folha de São Paulo, February 1994). The first is the now notorious banner headline from the Sunday Ttmes' self-righteous campaign to "search for the truth" by casting doubt over the causal role of HIV in AIDS. The second is an encouraging and straightforward message from an editorial in an equally prestigious and widely read Brazilian newspaper in the run up to Carnival.

It is instructive to consider how a country's attitudes to sex and HIV/AIDS are reflected in its media coverage and public health campaigns. In Brazil the HIV prevention campaign on television does not depict falling slate-grey headstones or funeral wreathes, but an attractive young girl and inflated condoms gyrating to dance music. Billboards do not display bloodstained syringes or mournfully advise "Don't Die of Ignorance"; instead there are brightly coloured condoms, party streamers and a caption saying "Carnaval Bem Transado" (this double entendre can be interpreted as "Carnival - Well Done" or the verb 'transar' can be translated into its more colloquial usage "to make love"). Even the President gets in to the spirit of things, not by calling for a return to family values, but by being photographed holding hands with a model who is visibly not wearing any knickers - he does not resign.

Carnival is seen as a time when sexual activity happens more freely; this is accepted and the message of the HIV campaign in the run up to Carnival was a simple one: "Use a condom". During Carnival itself the activity of the HIV campaign increased with non-governmental organisations (NGOs) such as GAPA (Grupo de Apoio à Prevenção da AIDS) and the Department of Health distributing thousands of condoms on the streets. One of the floats in the Carnival parades used gigantic multicoloured condoms and safe-sex as its theme.

AIDS is a massive problem in Brazil; the country is top of the league for cumulative cases in Latin America and the Caribbean and in the top three worldwide (Lima et al, 1992). Heterosexual transmission is increasing rapidly, exemplified by the falling male to female ratio of new AIDS cases: 29:1 in 1985 and $4: 1$ in 1993. In 1992 . $24 \%$ of new adult AIDS cases were due to heterosexual transmission; incomplete figures from 1993 suggest that the percentage is rising. Among women, 49\% of new AIDS cases are caused by heterosexual transmission (Ministério de Saúde, 1993). Various studies, primarily of patients in contact with treatment agencies, have shown alarmingly high prevalence rates for HIV, for example among intravenous drug misusers prevalence figures of between $32 \%$ and $76 \%$ have been reported; for transvestite prostitutes in Rio de Janeiro 37\%; for street children also in Rio 13\%; and for female prisoners in São Paulo 18\% (Lima et al, 1992). Thirty-four per cent of all AIDS cases have been reported in São Paulo City.

Behind the campaigns and propaganda lie various obstacles to the more general use of condoms in Brazil. First, for the 20 million or more Brazllians who live well below the poverty line there is the simple problem of cost. The World Bank, the North American Foundation for Family Health and the Brazilian Ministry of Health have all examined this issue independently and concluded that Brazilian condoms are among the most expensive in the world. They cost about US\$1.00 per condom compared to US\$0.05 in Europe and the USA. Indeed North Americans and Europeans use about eight times as many condoms as Brazilians.

The World Bank investigated the problem in 1991 and found that about 45 million condoms had been sold in Brazil that year, through approximately 30000 outlets and that they had been produced by just four domestic firms, all of which claimed excess capacity (World Bank, 1992). Federal law requires that all condoms manufactured in Brazil be made from domestically produced latex, the quality of which is below international standards. Imported condoms are subject to an array of rules and tariffs which render them prohibitively expensive, thus inhibiting real international competition in the condom market. The World Bank has requested that the Federal Government eliminate tariffs on 
imported condoms and latex and lift requirements to use domestically produced latex. The government has responded by announcing that it intends to eliminate one of the taxes on imported condoms.

Another problem is that condoms are currently available through a narrow range of outlets mainly pharmacies and supermarkets. The government's own co-ordinator of the National AIDS Prevention Programme, Lair Guerra, wants to increase the variety of outlets to include bars and public toilets. The World Bank is recommending an approach it describes as "social marketing". As an example it cites a scheme where subsidised condoms imported from Asia were being sold for US\$0.16 through outlets such as public toilets, motels and brothels in conjunction with an advertising campaign to raise awareness.

A more intractable problem is how to get the safe sex message across to high risk groups, as well as to the significant minority of Brazilians who are illiterate, do not read newspapers or do not own a television set. Non-governmental organisations have an important role to play here. The organisation GAPA has done much pioneering outreach work with high risk groups in Brazil and at the Carnival in São Paulo its members distributed 20000 fans with attached condoms and information about HIV/AIDS. The AIDS specialist Drauzio Varella, with financial support from the Colégio Objetivo, recently distributed a safe-sex comic-strip to 4500 prisoners in São Paulo's largest prison. The comic-strip featured a character called Vira-Lata (Street Dog), himself an ex-convict, and depicts his various sexual adventures in explicit detail; however, he is always seen using a condom. The World Bank is due to distribute 30 million condoms this year through NGOs and state/municipal AIDS/HIV prevention programmes.

Two recent surveys undertaken in Brazil illustrate some of the difficulties that lie ahead. The first was a study of 955 motel users (in Brazil many couples rent motel rooms overnight or by the hour to have sex) (Ministério de Saúde, 1992). While $81 \%$ of users considered condom use important, only $14.5 \%$ used condoms. Common reasons for not using condoms were: loss of sensation, discomfort and difficulty in putting them on. However responses to open questions suggested that many people saw condoms solely as contraceptives or felt that they did not need to use them because their partner was faithful. The second study was of Brazilian teenagers above the age of 14 and currently attending school (Folha de São Paulo, 1994). The survey was conducted by the Foundation for the Development of Education (FDE) and was performed in 1992 and again in December 1993. The responses showed that $52 \%$ of teenagers had had their first sexual contact between the ages of 13 and 15 and a further $32 \%$ between 16 and 18 . Fifty-seven per cent were using condoms on a regular basis (compared with $43 \%$ in 1992). However, among those not using condoms, $41 \%$ said they did not use them because they had confidence in their sexual partner and $22 \%$ because they were in a steady relationship. These results, whilst suggesting a favourable change in attitudes to condom use among young people, leave no room for complacency.

Campaigns need to emphasise that condoms are being recommended primarily for their protective properties rather than as contraceptives. With $24 \%$ of new AIDS cases due to heterosexual activity, $10 \%$ to bisexual activity and $26 \%$ to intravenous drug misuse (Ministério de Saúde, 1994), young heterosexual couples in steady relationships are still at risk and need to be persuaded of the importance of condom use.

With this emphasis on condoms there is a danger of overlooking the other major route of HIV transmission in Brazil - the sharing of needles and syringes between intravenous drug misusers. The co-ordinator of the Programme for Prevention of AIDS among Intravenous Drug Users at the Department of Health, Dr Fábio Mesquita, tried to implement a needle exchange programme in the city of Santos, which has a very high prevalence of drug users with HIV and AIDS. The scheme was hastily closed down by the Justice Department on the grounds that the distribution of needles and syringes to drug users was illegal. There are still no needle exchange schemes in Brazil and Dr Mesquita was subsequently dismissed from his job (Previnase, 1994). Clearly condoms are the foundation of any HIV prevention programme but the huge problem of transmission among intravenous drug users needs to be addressed. NGOs are actively working in this area, the government is lagging behind, while the media show little interest.

\section{References}

Lima. E., Bastos, F., Telles, P. \& Ward. T. (1992) Injectingdrug users and the spread of HIV in Brazil. AIDS and Public Policy Journal. 7, 170-74.

MINISTERIO DA SAÚDE (1992) Camisinhas. AIDS y DSTexperiéncias que funcionam, 1, 21.

- (1993) Boletim Epidemiológico AIDS, 6 (10).

Previnase (Pubicação do GAPA) No. 15. March/April/May 1994, p 6.

WORLD BANK (1992) Brazil - AIDS and STD Control Project. Brazil: World Bank.

John Dunn, CNPq Visiting Researcher, Departamento de Psiquiatria, Escola Paulista de Medicina, Rua Botucatú, 740, São Paulo-SP, Brazil, 04023-900 